\title{
A INCLUSÃO EXCLUDENTE DE PESSOAS COM DEFICIÊNCIA: DO DISCURSO DE CIDA- DANIA À PRÁTICA DAS POLÍTICAS HABITACIONAIS NO BRASIL
}

\author{
Anna Paula Lombardi", Cicilian Löwen Sahr ${ }^{* *}$ \\ * Bacharel, mestre e doutoranda em Geografia pela Universidade Estadual de Ponta Grossa. \\ ** Geógrafa, Professora dos Programas de Pós-graduação em Geografia pela Universidade Estadual de Ponta Grossa e Universidade Federal \\ do Paraná, Pesquisadora CNPq.
}

\begin{abstract}
Resumo: Neste artigo apresenta-se uma reflexão sobre a inclusão socioespacial de pessoas com deficiência. 0 objetivo central é avaliar o discurso e a prática efetiva quanto à inclusão desses sujeitos nas políticas públicas brasileiras. A análise foca os programas habitacionais e tem como recorte espacial a cidade de Ponta Grossa, no estado do Paraná (Brasil). 0 termo "pessoa com deficiência" passa a ser utilizado no Brasil a partir de 2008 com o intuito de defender a igualdade, em termos de direitos e dignidade, desse segmento populacional em relação aos outros. Nas políticas habitacionais, o termo passa a ter um emprego imediato no programa federal "Minha Casa, Minha Vida". 0 discurso que embasa tal programa prevê a garantia de acessibilidade para as pessoas com deficiência. Na prática efetiva, entretanto, quando se avalia a sucessão dos programas habitacionais implantados em Ponta Grossa, observa-se que a lógica de exclusão socioespacial não apresenta nenhuma ruptura ao longo do tempo, nem mesmo no programa mais recente. 0 que diferencia es se programa dos anteriores é: a) a destinação de um percentual das unidades às pessoas com deficiência; e b) a adaptação do espaço interno das casas para cadeirantes. Quanto à acessibilidade à infraestrura, equipamentos e serviços públicos, esse segmento não é atendido, sendo excluindo da vida no bairro e na cidade. Assiste-se, assim, a uma inclusão excludente desse segmento em termos socioespaciais.
\end{abstract}

Palavras-chave: Inclusão socioespacial, pessoas com deficiência, política habitacional, Ponta Grossa (Paraná).

\section{Introdução}

A construção de uma sociedade em que todos tenham as mesmas oportunidades para participarem plenamente da vida social é uma meta a ser perseguida. Para que se avance em direção a inclusão de todos na sociedade, sem distinção de grupos, é necessário existir o compromisso dos órgãos responsáveis pelas iniciativas de adequar os espaços. Apenas com promoção da acessibilidade é possível permitir a inclusão socioespacial das Pessoas com Deficiência (PcD).

As PcD, de modo geral, apresentam as piores perspectivas de saúde, níveis mais baixos de escolaridade e pouca participação econômica. As más condições de vida se devem as barreiras vivenciadas por elas no próprio local de moradia e no acesso aos serviços e equipamentos urbanos. Desta forma, saúde, educação, emprego, transporte e habitação continuam a ser uma problemática cotidiana.

Segundo Lanna Junior, "ser uma pessoa com deficiência é, antes de tudo, ser pessoa humana". (2010, p.17). Considerando esta afirmativa, torna-se necessário viabilizar uma sociedade inclusiva. No Brasil, apenas nos últimos anos as PcD começam a ter visibilidade na sociedade. Esse grupo vem se mobilizando e reivindica o direito da inclusão nos mais diversos espaços e o reconhecimento da diversidade humana.

As políticas habitacionais brasileiras, até pouco tempo atrás, não se voltavam - nem mesmo em seus discursos - para às PcD. Apenas recentemente, o Programa "Minha Casa Minha Vida" (MCMV) vem adotando iniciativas de inclusão socioespacial através da construção de habitações adaptadas. Todavia, não basta se pensar apenas no espaço interno das moradias, é preciso garantir que essas pessoas possam realizar atividades cotidianas como pagar contas, fazer compras, ir ao médico, ir à escola, ter lazer, entre outros.

Desta forma, buscou-se avaliar o discurso de cidadania e a prática efetiva na inclusão das $\mathrm{PcD}$ nas políticas públicas brasileiras. A análise se aprofunda para os programas habitacionais construídos na cidade de Ponta Grossa, estado do Paraná, ao longo do tempo. Para compor o artigo evidenciam-se quatro momentos. No primeiro tem-se as reflexões de caráter teórico, que se voltam às questões das PcD. Num segundo momento, avalia-se o limite tênue entre inclusão e exclusão socioespacial. Num terceito momento se analisam as lutas e conquistas das PcD. Num quarto momento, as reflexões se articulam a uma base empírica: os pro- 
gramas habitacionais presentes no espaço urbano de Ponta Grossa.

\section{Pessoa com deficiência e sociedade inclusiva: trajetórias de uma linguagem expressa}

As oportunidades para PcD não passaram por mudanças significativas ao longo do tempo, o que mudou foram às práticas sociais representadas na sociedade. A PcD "não deixou de ser vista como um ponto fora da curva de normalidade, apenas passou a serem utilizados canais mais sofisticados e eficazes para tratar as questões ao tratamento dos indivíduos desviantes". (GERALDO, 2013, p. 22-23).

Considerando isso, entende-se a "deficiência" como uma dimensão da diversidade. Ela é concebida como um processo histórico de atribuições de características e significados ao que é estimado diferente, e tem suas bases alicerçadas nas relações de poder vigente, no conhecimento produzido e compartilhado e na maneira como a sociedade está organizada. (FREITAS, 2010).

Essas relações de poder também são identificadas nas formas como a sociedade denomina às PcD, sendo muitas destas denominações expressões de uma negação social. Segundo Sassaki (1997), a construção de uma verdadeira sociedade inclusiva passa também pelo cuidado das expressões para se denominar uma PcD. Na linguagem se expressa, voluntariamente ou involuntariamente, o respeito ou a discriminação.

Os termos pejorativos - aleijado, defeituoso físico, incapacitado, inválido, incapazes, entre outros - são os rótulos colocados pela sociedade. De certa forma, tratase de um estigma, que se refere a um atributo de caráter altamente depreciativo que se coloca ao outro. As PcD são colocadas em uma posição com valores diferentes e menores aos demais indivíduos. (BARTALOTTI, 2006).

Não são somente os indivíduos da sociedade que fazem referência as PcD de forma pejorativa, errada e incerta. Grandes convenções, que ocorreram a partir de 1980, representam os equívocos ao se fazer referência a uma PcD. 0 "Ano Internacional das Pessoas Deficientes", que aconteceu em 3 de dezembro de 1981, foi um evento em nível mundial, que mencionava as PcD de forma equivocada. "Pessoas deficientes" era uma forma de não atribuir a deficiência como um valor de incapacidade naquela época. (LANNA JÚNIOR, 2010, p. 24).

No período de 1985 a 1990 os termos "pessoa portadora de deficiência" e "portadores de deficiência" eram os termos mais usados. Em 1988, na Constituição Federal e no período que a sucedeu, de 1990 a 2000, foi utilizado o termo "portador de necessidades especiais". Assim, por muitos anos a expressão "pessoas portadoras de deficiência" e "pessoas com necessidades especiais" foram utilizadas para denominar esse grupo. 0 objetivo era identificar a deficiência como um detalhe da pessoa. (SILVA e IACOBUCCI, 2013).

Essa expressão inadequada foi adotada na
Constituição Federal de 1988, bem como em todas as leis e políticas pertinentes ao campo das 'deficiências'. Os conselhos, coordenadorias e associações passaram também a incluí-la em seus documentos oficiais. Os "eufemismos foram adotados, tais como pessoas com necessidades especiais e portadores de necessidades especiais", contribuindo para estigmatizá-los. (LANNA JÚNIOR, 2010, p. 17).

Lanna Júnior (2010) menciona o grande descontentamento das PcD a esses eufemismos, os quais se deve ao fato de o adjetivo "especial" criar uma categoria que não combina com a luta por inclusão e por equiparação de direitos. Para as PcD, na luta política não se busca ser "especial", mas, sim, ser cidadão. A condição de "portador" passou a ser questionada pelas PcD por transmitir a ideia de que a deficiência é algo que se porta e, portanto, não faz parte da pessoa. Além disso, enfatiza a 'deficiência' em detrimento do ser humano.

A mudança veio com a denominação "pessoas com deficiência", termo aprovado pela Organização das Nações Unidas (ONU) em 2006. No ano seguinte o Brasil torna-se seu signatário, sendo instituído o termo através de emenda Constitucional em 2008. A inclusão do substantivo "pessoa" foi uma forma de evitar a coisificação, se contrapondo à inferiorização e desvalorização associada aos termos pejorativos usados até então.

O termo "pessoas com deficiência" passou a ser a expressão adotada na sociedade moderna para nomear esse grupo social até os dias atuais:

Em oposição à expressão "pessoa portadora", "pessoa com deficiência" demonstra que a deficiência faz parte do corpo e, principalmente, humaniza a denominação. Ser "pessoa com deficiência" é, antes de tudo, ser pessoa humana. É também uma tentativa de diminuir o estigma causado pela deficiência. A expressão foi consagrada pela Convenção sobre os Direitos das Pessoas com Deficiência, da Organização das Nações Unidas (ONU), em 2006. (LANNA JÚNIOR, 2010, p. 17).

Portanto, a sociedade necessita estar preparada para respeitar, reconhecer e acolher as diferenças humanas. Em princípio, a denominação "pessoa com deficiência" foi utilizada para defender a igualdade em termos de direitos e dignidade entre este segmento e as demais, o que exige a equiparação de oportunidades atendendo às diferenças individuais. Neste sentido, o avanço da inclusão socioespacial está relacionado ao desenvolvimento da sociedade e a luta política das próprias PcD.

\section{Entre inclusão e exclusão socioespacial: um limi- te extremamente tênue}

A inclusão socioespacial significa a construção de uma sociedade em que todos tenham a oportunidade e 
o apoio de que necessitam para participar plenamente da vida em sociedade. A dignidade é alcançada de maneira plena quando o sujeito consegue desenvolver seu potencial humano nas relações sociais. Assim, é a partir desse ponto de vista que a inclusão vem originando diversas questões, que serão abordadas na sequência, baseadas na complexidade de fatos que ocorrem nas práticas sociais na sociedade.

A inclusão socioespacial para as PcD é uma questão que vem sendo analisada sob as mais diversas óticas. A inclusão é mencionada porque existem pessoas que pelos mais variados motivos, encontram-se alocados em uma categoria visivelmente específica, a da exclusão. Desse modo, só se pode falar em inclusão porque existe a exclusão. A exclusão é definida como uma desvantagem, é algo indesejável que fere a dignidade humana, principalmente quando se trata de PcD. (BARTALOTTI, 2006).

A discriminação seguida da exclusão ocorre por inúmeros fatores, podendo ser compreendida pela forma de organização do espaço ao longo do tempo. Nos diferentes períodos da história da sociedade, condicionantes estruturais determinaram socialmente as posições de dependência, limitação, carência e inferiorização dos sujeitos que não eram considerados semelhantes aos demais. (BIANCHETTI, 1998).

Verás (2006) menciona que desde os tempos coloniais - passando pelo Brasil do Império, das Repúblicas Velha, Nova e Contemporânea, agravando-se na ditadura militar - os processos sociais excludentes se fazem presentes. Portanto, a exclusão para as minorias possui diferentes dimensões, é multidimensional, indo desde a precariedade econômica e social, instabilidade conjugal, vida social e familiar inadequada, até o baixo nível de participação nas atividades sociais. Trata-se de uma espiral viciosa de produção da exclusão.

Na sociedade brasileira contemporânea verifica-se a exclusão de inúmeros grupos sociais, sendo bem visível a exclusão das $\mathrm{PcD}$, que são segregadas das mais variadas formas, ora explícitas, ora não. Existem aqueles que nem mesmo conseguem acesso aos direitos mínimos garantidos pela Constituição, o que engloba os campos de habitação, educação, saúde e serviços. Neste caso, a exclusão aparece como não acesso aos benefícios da urbanização. Essa exclusão inclui a ausência de poder, assim, a privação de poder de ação e representação e, nesse sentido, a exclusão social tem que ser pensada também a partir da questão da democracia. (VERÁS, 2006).

$\mathrm{Na}$ análise da questão urbana se evidencia claramente a perversa lógica da exclusão, presente nas várias formas de relações desiguais entre sujeitos, sendo essas econômicas, sociais, culturais e políticas. Santos (1987) ressalta a urbanização como processo excludente, contribuindo na reflexão sobre a redemocratização brasileira, sobretudo, para a importância do lugar, do território e, desse ângulo, a questão da cidadania. Para o autor, "cada homem vale pelo lugar onde está. 0 seu valor como produtor, consumidor, cidadão depende de sua localização no território (...)". (1987, p.81).

Assim, a probabilidade de ser mais ou menos cidadão depende do ponto de vista do território onde se está. Santos (1987) deixa isso claro com o seguinte pensamento sobre a exclusão urbana:

As condições existentes nesta ou naquela região determinam essa desigualdade no valor de cada pessoa, tais distorções contribuindo para que o homem passe literalmente a valer em função do lugar onde vive. Essas distorções devem ser corrigidas em nome da cidadania. (SANTOS, 1987, p. 112).

Sawaia (2006) menciona os aspectos culturais da reflexão, de viés econômico, que Santos faz em relação à exclusão urbana. Para ele, a cidadania é também o direito de permanecer no lugar, no seu território identitário, o direito ao seu espaço de memória. 0 capitalismo predatório e as políticas urbanas, que privilegiam interesses privados, acabam por descaracterizar bairros tradicionais e expulsar moradores, privando-os do direito a raízes.

Portanto, o conceito de exclusão se refere tanto a processos quanto a situações consequentes, e é mais abrangente que conceito de pobreza, compreendido frenquentemente como algo exclusivo à renda. Tal conceito estabelece a natureza multidimensional dos mecanismos através dos quais "os indivíduos e grupos são excluídos das trocas sociais, das práticas componentes e dos direitos de integração social e de identidade (...), ele vai além da participação na vida do trabalho englobando outros campos (...)" (VERÁS, 2006, p.34).

Logo, o tema inclusão socioespacial para as PcD no Brasil vem sendo tratado como uma forma de eliminar práticas de exclusão que ocorrem nas relações da sociedade moderna. A mesma sociedade que aparenta ter uma preocupação em incluir as $\mathrm{PcD}$, passa a ser a primeira que as desampara. De um lado, tem-se uma postura caridosa, em sentido negativo, e de outro, a conduta excludente num aparente paradoxo. Essa prática, todavia, é bem característica do mecanismo que insiste em deixar às margens essas pessoas. (BEVERVANÇO, 2001).

Santos (2004, p. 213) específica a importância de se compreender "a construção do espaço que é obra da sociedade em sua marcha histórica ininterrupta". Nas primeiras civilizações já ocorria à hierarquização entre grupos. De um lado existia a tolerância e assimilação, e de outro havia o costume da eliminação, menosprezo ou a segregação.

No caso do Brasil, a Constituição de 1988 embora garanta os direitos sociais universais à sociedade, não apresenta dispositivos suficientes para atender certos segmentos da sociedade enquanto sujeitos de direito, como é o caso das PcD. O Estado é uma instância que deveria representar o interesse universal, todavia, embora o faça no discurso, em termos práticos representa 
apenas uma classe.

0 Estado deveria ser ágil para atender certas demandas. 0 descontentamento dos sujeitos que reivindicam o direito de acessibilidade, por exemplo, requer do Estado que se tomem atitudes para inquietar as insatisfações, as quais vão repercutir na implantação de políticas públicas para tal propósito. Segundo Teixeira (2002), as "políticas públicas" são diretrizes que possuem princípios norteadores de ação do poder público, há nelas também regras e procedimentos para as relações entre poder público e sociedade, mediações entre atores da sociedade e do Estado.

Neste sentido, o grande obstáculo em relação às políticas públicas encontra-se na predominância do neoliberalismo no caráter das políticas e/ou programas. Uma política pública requer a intervenção do Estado em várias áreas de atuação dos indivíduos e, para o neoliberalismo, o equilíbrio social é resultante do livre funcionamento do mercado, com um mínimo de ação do Estado. Deve existir o mínimo de regulamentação possível e as políticas distributivas devem compensar desequilíbrios mais graves e, portanto, passam a ter o caráter cada vez mais seletivo e não universalizante. (TEIXEIRA, 2002).

Neste contexto, o neoliberalismo propagou uma saída política, econômica e jurídica específica para a solução dos problemas cíclicos da economia do mundo capitalista. Provocou uma modificação organizacional, estrutural e funcional do Estado, minimizando o seu papel em relação à garantia dos direitos sociais. A principal preocupação foi limitar a esfera de influência do público no privado. Desta forma, "a globalização do capitalismo e de seu comparsa político, o neoliberalismo, funciona, de forma conjunta, para naturalizar o sofrimento, para destruir a esperança e para aniquilar a justiça." (GIRON, 2008, p.19).

No Brasil, as políticas econômicas atuais acabaram por provocar, não políticas de exclusão e, sim, políticas de inclusão precária e marginal. Os rebatimentos do neoliberalismo nas políticas sociais são desastrosos. Estas passam a ter um caráter eventual e complementar por meio de práticas fragmentadas e compensatórias. Piana (2009, p.34) menciona que no neoliberalismo "o Estado só deve intervir com o intuito de garantir um mínimo para aliviar a pobreza e produzir serviços que os privados não podem ou não querem produzir, além daqueles que são, a rigor, de apropriação coletiva". Assim, os direitos sociais tornam-se mercadorias e o movimento econômico restringe a esfera social da cidadania em favor da projeção do mercado.

A despeito de suas limitações estruturais, discutidas anteriormente, as políticas públicas, se bem formuladas e implementadas, podem contribuir para a inclusão socioespacial e para a conquista de direitos iguais na sociedade para as PcD enquanto sujeitos de direitos. Na atualidade, o processo de inclusão socioespacial para as PcD ainda é bastante ineficiente. $\mathrm{Na}$ prática existe o esforço das $\mathrm{PcD}$ em tentar garantir uma sociedade de equidades de direitos e inclusão nos mais diversos espaços. Todavia, ainda falta o compromisso da sociedade e do Estado para contribuir neste processo de inclusão socioespacial. A realidade é que a maioria das PcD são não-cidadãos, pois não conseguem exercem a cidadania plena.

\section{Por uma inclusão socioespacial: lutas e conquis- tas das Pessoas com Deficiência}

É a conquista por direitos que proporciona a inclusão social de $\mathrm{PcD}$ e é no espaço que acontecem às relações dos sujeitos. Portanto, o processo de produção socioespacial é assumido também através das lutas e movimentos criados com o intuito da igualdade social e de oportunidades nos mais diversos espaços. (SANTOS, 1987).

Os movimentos sociais organizados no âmbito da sociedade retratam o descontentamento de uma cultura que não beneficia o todo. Há a necessidade de se propor novas alternativas para grupos como o das PcD, que ao longo do tempo permaneceram excluídas. Elas reivindicam e, vão mais além, contrapõem-se ao planejamento e as gestões conservadoras de uma sociedade dos sujeitos ideais.

O movimento das PcD é um importante agente modelador do espaço, capaz de protagonizar resistências e pressões que abrem caminhos de autonomia. Este movimento, presente no mundo todo, é determinante para se avançar em termos de "desenvolvimento socioespacial”. (SOUZA, 2006). Assim, as mudanças socioespaciais que vem sendo alcançadas ao longo dessa luta, possibilitam a continuidade da trajetória na busca por uma sociedade mais justa, com oportunidades iguais para todos.

Segundo Crespo (2009, p.145), "a luta pelos direitos das PcD tem mais de 50 anos de história". Inicia-se nos Estados Unidos e na Europa, depois da segunda Guerra Mundial. Este período foi marcado pela volta de ex-combatentes mutilados, que receberam grande impulso a partir de 1960, com as lutas pelos direitos civis e por espaços acessíveis.

Sassaki (1997) esclarece que o movimento das PcD no Brasil foi impulsionado pelo cenário internacional, com a motivação de outros movimentos das PcD no mundo. 0 movimento dos "Tetras Rolantes" nos EUA em 1962, liderado por Ed. Roberts, é um exemplo de movimento com força política que promoveu as primeiras guias rebaixadas, possibilitando acessibilidade na Universidade da Califórnia da cidade de Berkeley.

O Movimento da Vida Independente (MVI), criado também nos EUA em 1972, foi um dos mais importantes movimentos de PcD no mundo. Foi liderado pelas próprias PcD que apresentavam um quadro de deficiência severa, em sua maioria mutilados pela Guerra do Vietnã. 0 movimento se espalhou pelo mundo todo e inclusive no Brasil, trazido por militantes. Assim, o MVI se mostrou ativo nas lutas por direitos e força política. 
(CORDEIRO, 2007).

O movimento das PcD no Brasil se sustentou a partir da conjuntura da época, a do regime militar de 1964-1985, que não tinha em vista nenhuma política ou projeto voltado às $\mathrm{PcD}$. 0 processo de redemocratização brasileira e a promulgação pela ONU em 1981 do “Ano Internacional das Pessoas Deficientes" contribuíram para dar visibilidade ao movimento político das PcD.

Este movimento tornou ativos agentes políticos na busca por transformação da sociedade. 0 "Movimento pelos Direitos das Pessoas Deficientes" no Brasil motivou uma mobilização nacional por meio de uma coalizão criada em 1979. A Coalizão Pró-Federação Nacional de Entidades de Pessoas Deficientes, pela primeira vez, conseguiu congregar organizações de diferentes estados e tipos de deficiência, que se reuniram para traçar estratégias de luta por direitos. (CRESPO, 2009). Neste período as questões relacionadas à acessibilidade universal se tornaram mais visíveis no Brasil.

A Constituição de 1988, marco de mudanças no regime político democrático, foi fruto de um processo de articulação das forças políticas e sociais, entre elas a das PcD. A Constituição Cidadã, assim designada, consagrou juridicamente o princípio de que os direitos dos cidadãos à saúde, à educação, ao trabalho, à terra, à habitação, entre outros, são deveres do Estado, que deve cumpri-los mediante a implantação de leis e políticas públicas. Assim, foram criados, nas três esferas de Governo, diversos conselhos, dentre os quais os conselhos de defesa dos direitos das PcD. (ESCOREL e MOREIRA, 2008).

As Leis $\mathrm{n}^{\circ} 10.048$ e $^{\circ} 10.098$ de 2000 , bem como o Decreto $n^{\circ} 5.296$ de 2004, conhecido como o Decreto da Acessibilidade, foram essenciais para possibilitar acessibilidade aos espaços das cidades. Também a criação, em 2003, do Ministério das Cidades possibilitou uma atmosfera apropriada para o atendimento das necessidades das PcD. Duas secretarias deste Ministério, a de transporte e mobilidade urbana, bem como a de habitação, estão articuladas com o Programa "Brasil Acessível" e o Programa "Minha Casa Minha Vida" (MCMV), o qual vem destinando 3\% das casas construídas às PcD. (CÂMARA DOS DEPUTADOS, 2013).

0 programa de habitação MCMV voltado às $\mathrm{PcD}$ aponta em seu discurso a garantia de acessibilidade não só nos espaços internos das casas adaptadas, mas também no entorno destas. Primordialmente, deve-se ter infraestrura, equipamentos e serviços públicos adequados, que atendam a esse segmento. Todavia, apesar dos avanços na legislação brasileira, as PcD permanecem enfrentando dificuldades e vivem frequentemente em condições deploráveis devido à presença de barreiras físicas e sociais que impedem sua inclusão e plena participação na sociedade.

\section{As Pessoas com Deficiência nas políticas habi- tacionais: análise a partir de exemplos de Ponta Grossa/PR}

A cidade de Ponta Grossa, localizada na região Centro Sul do estado do Paraná, assim como outras cidades médias brasileiras, apresentou uma rápida evolução da população urbana. Em 1960, Ponta Grossa ultrapassou os 50.000 habitantes, em 1970 os 100.000 habitantes, em 1991 os 200.000 habitantes e em 2010 os 300.000 habitantes (IBGE, 1960, 1970, 1991 e 2010).

Essa rápida urbanização, não só em Ponta Grossa, exigiu do Estado ações que se voltassem para o atendimento da crescente demanda habitacional, sobretudo para o segmento de menor poder aquisitivo. As políticas públicas habitacionais foram demandadas aos governos federal, estadual e municipal, o que levou a criação de Companhias e Fundos de Habitação.

A construção de conjuntos habitacionais na periferia das cidades, atendendo a lógica de exclusão, foi o que preponderou ao longo das políticas habitacionais brasileiras. A localização dos conjuntos habitacionais no espaço urbano de Ponta Grossa é exemplo que comprova a inclusão excludente das políticas habitacionais. De um lado o segmento de menor poder aquisitivo é incluído nas políticas públicas, mas de outro é excluído pelo não acesso aos benefícios decorrentes da urbanização.

Segundo Scheffer (2003), no período entre 1967 a 1969 , sob os ditames da ditadura militar, surgem em Ponta Grossa os primeiros quatro conjuntos habitacionais para famílias de baixo poder aquisitivo, administrados pela primeira companhia de habitação instalada pelo poder público municipal, a Cohab-PG. (Figura 1). Esta companhia, com recursos reduzidos, não conseguiu dar continuidade as obras e foi vendida a Companhia Habitacional do Paraná (Cohapar), transferindo estes conjuntos para a responsabilidade e administração do governo estadual através de seu escritório regional de Ponta Grossa.

Da mesma forma que a Cohab-PG, a Cohapar continuou com o mesmo processo de periferização dos conjuntos habitacionais das famílias de baixa renda. Essa companhia realizou entre 1979 e 1999 a construção de 11 conjuntos em Ponta Grossa. As obras tanto da Cohab-PG como da Cohapar foram realizadas com recursos federais provenientes do Banco Nacional da Habitação (BNH). Paralelamente a atuação da Cohapar, a Cooperativa Habitacional dos Assalariados (Cohalar) teve uma contribuição na implantação de dois conjuntos na cidade, estes efetivados em 1991 e 1996 com recursos federais administrados pela Caixa Econômica Federal (CEF). (SCHEFFER, 2003).

Os oito conjuntos habitacionais implantados pela Companhia Habitacional de Ponta Grossa (Prolar) entre 1990 e 2005 também seguiram o mesmo padrão 
dos demais empreendimentos voltados às famílias de baixa renda. Portanto, é nítida a continuidade do processo de segregação socioeconômica da população em espaços mais periféricos da cidade. É dessa forma que os programas habitacionais voltados à população de baixa renda, foram colaborando, segundo Löwen Sahr

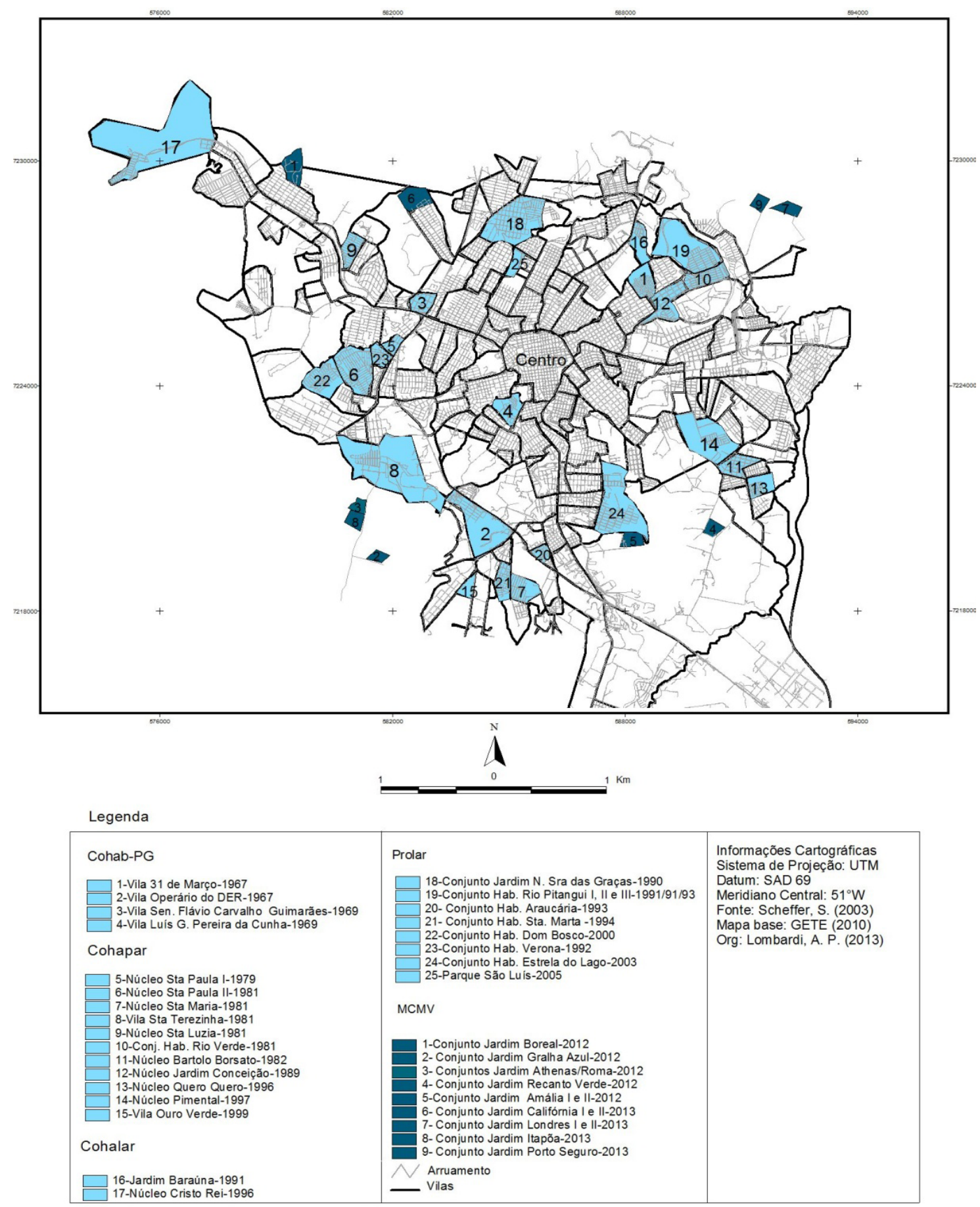

(2001), para a ampliação horizontal da malha urbana, característica esta que ainda predomina em Ponta Grossa, estimulando os vazios urbanos e a consequente especulação imobiliária.

Recentemente, entretanto, observa-se uma ruptura parcial de continuidade nas políticas habitacionais com um discurso aparentemente novo de inclusão socioespacial de PcD. Neste contexto aparece o Programa "Minha Casa Minha Vida" (MCMV), se apresentando como um instrumento de inclusão socioespacial tanto para a população de baixa renda, como também para as PcD dentro do segmento.
0 retrato demográfico de Ponta Grossa para o ano 2010 (IBGE, 2010) é o de uma população de 304.841 mil habitantes. Entre esta população total, 21\% (mais de 65.000 habitantes) é identificada com algum tipo de deficiência, seja física neuromotora, visual, auditiva, mental ou intelectual. Esse percentual, com variações para cima ou para baixo, representa grande parte das cidades brasileiras de mesmo porte.

Com o intuito de avaliar a aproximação e o distanciamento entre o discurso e a prática efetiva desse programa mais recente, toma-se os exemplos de Ponta Grossa. Essa cidade adere o programa de habitação 
MCMV em 11 de maio de 2009 através da sua Prefeitura Municipal, da Companhia de Habitação de Ponta Grossa (Prolar) e da Caixa Econômica Federal local. Desde o primeiro momento de instituição do programa MCMV no município, teve-se como prioridade atender famílias com renda de 0-3 salários, ou seja, famílias de baixa renda, destinando-se 3\% das habitações em cada conjunto às PcD. Outra prioridade foi o atendimento de famílias que vivem em áreas de risco, como os fundos de vale e regiões sujeitas a alagamento e ou deslizamentos.

Ponta Grossa foi uma das cidades brasileiras que mais recebeu recursos para a construção de moradias populares pelo MCMV. A cidade teve o recorde nacional em casas financiadas pelo programa. Somando os empreendimentos habitacionais em regime de condomínios, conjuntos e loteamentos, constituídos de casas entregues até julho de 2013, totalizaram-se 8.100 re-

Quadro 1 - Conjuntos habitacionais do Programa "Minha Casa Minha Vida" no espaço urbano de Ponta Grossa- PR que tiveram suas obras finalizadas entre $2011 / 2013$

\begin{tabular}{|c|c|c|c|c|c|c|}
\hline $\begin{array}{c}\text { Conjunto } \\
\text { Habitacional }\end{array}$ & $\begin{array}{c}\text { Casa } \\
\text { padrão } \\
\text { (n.) }\end{array}$ & $\begin{array}{c}\text { Casa } \\
\text { adaptada* } \\
\text { (n.) }\end{array}$ & Construtora & $\begin{array}{c}\text { Casa } \\
\text { padrão } \\
\left(\mathbf{m}^{2}\right)\end{array}$ & $\begin{array}{c}\text { Casa } \\
\text { adaptada } \\
\left(\mathbf{m}^{2}\right)\end{array}$ & $\begin{array}{l}\text { Ano de } \\
\text { entrega }\end{array}$ \\
\hline Athenas & 341 & 11 & $\begin{array}{c}\text { Piacentini } \\
\text { Curitiba }\end{array}$ & 36,77 & 46,61 & 2012 \\
\hline Amália I & 99 & 3 & $\begin{array}{l}\text { Saint- Gobain } \\
\text { Curitiba }\end{array}$ & 36,77 & 46,60 & 2013 \\
\hline Amália II & 399 & 11 & $\begin{array}{l}\text { Saint-Gobain } \\
\text { Curitiba }\end{array}$ & 36,77 & 46,60 & 2012 \\
\hline Boreal & 365 & 11 & $\begin{array}{c}\text { Yapó } \\
\text { Curitiba }\end{array}$ & 37,14 & 48,72 & 2011 \\
\hline Califómia I & 153 & 5 & $\begin{array}{c}\text { Yapó } \\
\text { Curitiba }\end{array}$ & 37,14 & 48,72 & 2013 \\
\hline Califómia II & 328 & 9 & $\begin{array}{c}\text { Yapó } \\
\text { Curitiba }\end{array}$ & 37,14 & 48,72 & 2013 \\
\hline Gralha Azul & 195 & 6 & $\begin{array}{c}\text { Piacentini } \\
\text { Curitiba }\end{array}$ & 36,77 & 46,61 & 2011 \\
\hline Itapoá & 500 & 15 & $\begin{array}{c}\text { Piacentini } \\
\text { Cunitiba }\end{array}$ & 36,77 & 46,61 & 2013 \\
\hline Londres I e II & 500 & 18 & $\begin{array}{c}\text { Piacentini } \\
\text { Curitiba }\end{array}$ & 36,77 & 46,61 & 2013 \\
\hline Roma & 249 & 8 & $\begin{array}{l}\text { Piacentini } \\
\text { Curitiba }\end{array}$ & 36,77 & 46,61 & 2012 \\
\hline Recanto Verde & 392 & 12 & $\begin{array}{c}\text { RPW } \\
\text { Ponta Grossa }\end{array}$ & 36,77 & 40,00 & 2012 \\
\hline Total de casas & 3.521 & 109 & & & & \\
\hline
\end{tabular}

Fonte: Prolar Org.: Lombardi, 2012

sidências. (FARIAS, 2013). Outras 4.300 estavam em construção para que se atingisse até o final de 2014 o montante de 12.400 casas $^{1}$. (Quadro 1).

A casa adaptada possui dimensões entre 40,00 e $48,72 \mathrm{~m} 2$, um pouco maiores que a casa padrão, buscando permitir a mobilidade de cadeirantes no seu interior. As adaptações nas casas do MCMV são especificamente para a PcD neuromotora, ou seja, para aquelas que se utilizam de cadeira de rodas. As pessoas que possuem deficiência visual e auditiva, por exemplo, são contempladas com casas padrão, sem adaptações. Em seu discurso na fase II, o programa garante "às PcD o direito da moradia adequada a sua condição física, sensorial, intelectual, com a contratação de 1,2 milhões de unidades adaptáveis, e a oferta de kits ${ }^{2}$ de adaptações em 3\% delas, conforme o tipo de deficiência". (SNPDPD, 2013, p.51).

A diferenciação das casas adaptadas segue, todavia, um único padrão, não garantindo adaptações as características individuais de seus moradores. Existem exigências previstas no padrão de acessibilidade (VACAREZZA, 2012), entre elas: a) rampa de acesso na entrada da casa; b) instalação de portas com maçanetas de alavanca e com no mínimo 80 centímetros de largura, permitindo a circulação de cadeira de rodas; c) largura mínima dos banheiros de 1,5 metros, com área de transferência ao vaso sanitário, descarga sanitária adaptada, instalação de barras de apoio e banco articulado; d) os interruptores e tomadas altas devem ser instalados a uma altura de um metro, para permitir o acionamento por pessoas em cadeira de rodas.

Via de regra, as casa adaptadas do MCMV em Ponta Grossa seguem a este padrão único de adaptação. Um ponto negligenciado é o das rampas de acesso na entrada da casa. Nos cinco primeiros conjuntos implementados na cidade, por exemplo, apenas três - Jardins Athenas, Roma e Gralha Azul - possuem rampa de acesso ligando o passeio até a entrada da casa. Não houve esta preocupação por parte das construtoras responsáveis pelos Jardins Boreal e Recanto Verde.

${ }^{1}$ Para aprofundamento da questão específica do MCMV em Ponta Grossa ver Lombardi e Löwen Sahr (2013) e Lombardi (2014).

${ }^{2}$ Conteúdo dos Kits para PcD visual: Acionadores elétricos com sinalização em relevo e instalação padrão, contraste de cor entre o piso, parede e porta, fita refletiva para a sinalização de degraus e escadas entre outros. Já para os Kits para PcD Auditivas: Companhia de sinalização luminosa estroboscópica e vibrações em todos os cômodos. 
Fazendo uma reflexão sobre os três primeiros anos do MCMV, observa-se um avanço em termos de inclusão socioespacial das PcD, todavia, trata-se de uma inclusão seletiva. Todos os 11 conjuntos do programa ofertam habitações adaptadas. Das 3.630 habitações destinadas à população de baixa renda, 109 são adaptadas. Há que se ressaltar, todavia, que as adaptações só se adéquam à cadeirantes. Assim, permanecem excluídos do programa as pessoas que tem deficiências diferentes da considerada "padrão". Falta, portanto, reduzir a distância entre o discurso do MCMV e a realidade encontrada. A demanda por casas adaptadas é muito superior à oferta, mesmo considerando apenas o caso dos cadeirantes, e há ainda todas as outras modalidades de deficiência a serem contempladas.

Os maiores problemas, entretanto, não estão nas habitações em si, mas sobretudo à precária infraestrutura existente nos conjuntos. Em termos de serviços de luz, água e esgoto, os conjuntos são bem servidos. Isso vale também para a pavimentação e o passeio. A maioria oferece na calçada de passeio o piso podo tátil, destinado aos deficientes visuais. A precariedade se encontra na oferta de equipamentos públicos como escolas e postos de saúde, bem como, de estabelecimentos de lazer e comerciais nos conjuntos. Somam ainda as deficiências no transporte coletivo, com pouca oferta de horários de circulação de ônibus nestes locais extremamente periféricos.

As percepções das PcD com relação as novos conjuntos em que residem atualmente podem ser observadas no Quadro 2, onde foram organizadas as falas das PcD ou de seus responsáveis.

Como se observa no Quadro 2, as principais desvantagens de ir morar nos conjuntos são a ausência de Centros Municipais de Educação Infantil, Escolas com Ensino Fundamental I e II, Escolas de Ensino Médio, Posto de Saúde e mercados. Também não há locais para diversão e lazer, não a igrejas, farmácias e pequenos comércios. Exceção é o caso de uma escola municipal nas proximidades dos Jardins Gralha Azul, Athenas e Roma, todavia, esta não atende às especificidades das crianças com deficiência. As PcD precisam se deslocar para o centro da cidade, bairros distantes e/ou vilas mais próximas para realizarem suas atividades cotidianas.

A Prolar, que é a companhia de habitação responsável pelo programa na cidade, ressalta que a responsabilidade sobre os equipamentos públicos é do poder municipal, que deve garantir o acesso da população a estes e também garantir o desenvolvimento como direito social. Os conjuntos implantados antes do MCMV em Ponta Grossa, em sua maioria, muito lentamente conseguiram evoluir em termos de infraestrutura e equipamentos básicos. Nos conjuntos do MCMV, se não houver iniciativas efetivas na implantação de estratégia social, econômica e urbana, estes terão o mesmo destino que os demais.

Neste sentido, o programa MCMV vem passando por reformulações, como esclarece a assistente social da Prolar ${ }^{3}$. Para os empreendimentos que foram contratados a partir do final de 2012, o poder público municipal vem assinando um Termo de Compromisso de que deverá construir e/ou ampliar os equipamentos públicos em um raio de até $2,5 \mathrm{~km}$ do conjunto habitacional instalado. Todavia, observa-se que o discurso se afasta da realidade. Oferecer apenas o mínimo para os grupos de minorias e desfavorecidos ainda é uma grande estratégia dos governos para manter a ordem vigente.

O programa MCMV na maioria das cidades brasileiras, como aponta Geraldo (2013), está voltado à lógica do mercado imobiliário, a qual altera o foco do espaço residencial urbano como valor de uso e amplia as estratégias de apropriação pelos agentes econômicos (construtoras e incorporadoras) como valor de troca. Sendo assim, fica para segunda opção à questão social das famílias de baixa renda. Nos conjuntos do MCMV há mais evidências de exclusão do que inclusão socioespacial, sobretudo quando se depara com o grupo das PcD, para os quais a acessibilidade é a principal garantia do exercício de cidadania.

Quadro 2 - Percepções das PcD em relação aos problemas encontrados nos conjuntos do "MCMV"

\begin{tabular}{|c|c|}
\hline $\begin{array}{l}\text { A casa é própria, mas não é tudo aquilo, o } \\
\text { encanamento não tinha as ligações corretas, } \\
\text { goteiras na casa, aquecedor solar nunca } \\
\text { funcionou, descarga adaptada estragada, } \\
\text { fechadura das portas ruins e a falta do carteiro } \\
\text { (PcD1). }\end{array}$ & $\begin{array}{l}\text { As mulheres não têm empregos, se sentem } \\
\text { abandonadas. Falta posto, creche, não tem } \\
\text { associação. As mães se batem com as crianças, não } \\
\text { tem trabalho para as mães. Falta segurança. A vila } \\
\text { cresce e cresce também os problemas. ( }(\mathrm{PcD} 2)\end{array}$ \\
\hline $\begin{array}{l}\text { Dificuldades com a escola. O transporte da } \\
\text { minha filha não passa mais, pois o conjunto é } \\
\text { longe e é gasto demais. Também não tem posto } \\
\text { de saúde. ( } \mathrm{PcD} 3 \text { ). }\end{array}$ & $\begin{array}{l}\text { Por ser muito longe as dificuldades aumentaram, } \\
\text { falta posto de saúde por causa da deficiência da } \\
\text { minha filha. ( } P c D \text { ). }\end{array}$ \\
\hline $\begin{array}{l}\text { Segurança é zero, não passa polícia, piorou um } \\
\text { pouco, antes os equipamentos eram na frente da } \\
\text { minha casa. ( } \mathrm{PcD} \text { 5). }\end{array}$ & $\begin{array}{l}\text { O lugar é longe... } \\
\text { infraim, não tem nada de } \\
\text { (PcD6). }\end{array}$ \\
\hline $\begin{array}{l}\text { Não tem postos de saúde, correio... o da Santa } \\
\text { Terezinha nunca tem médico. ( } \mathrm{PcD} 7) \text {. }\end{array}$ & $\begin{array}{l}\text { Dificuldades com o transporte, o onibus demora e } \\
\text { para chegar ao centro precisa pegar mais um ônibus. } \\
\text { (PcD8). }\end{array}$ \\
\hline $\begin{array}{l}\text { Está ruim, não tem posto de saúde, creches, } \\
\text { escolas, mercado, farmácia. Não tem emprego } \\
\text { para as mulheres. (PcD9). }\end{array}$ & $\begin{array}{l}\text { O material da casa é ruim, frágil, nem toda peça é } \\
\text { azulejada, o chão é bruto de cimento, não tem } \\
\text { associação de moradores, não há segurança, o } \\
\text { parquinho para as crianças foi todo destruído, não } \\
\text { melhorou, ficou na mesma situação. (PcD10). }\end{array}$ \\
\hline $\begin{array}{l}\text { Ficou ruim, lugar longe, o meu filho não vai } \\
\text { mais para escola é contra-mão. (PcD11). }\end{array}$ & $\begin{array}{l}\text { A casa é boa, mas o problema é ser muito longe de } \\
\text { tudo, o ônibus é de qualidade é bom, mas, é } \\
\text { pequeno é tem muito gente, à situação piorou. } \\
(\mathrm{PcD} 12) \text {. }\end{array}$ \\
\hline
\end{tabular}

Fonte: Pesquisa de campo, 2013 Org: Lombardi, 2015 


\section{Considerações Finais}

O programa MCMV vem dando a oportunidade para as PcD de baixa renda terem sua casa própria adaptada com custo acessível. Esse mérito do programa é reconhecido pelas PcD beneficiadas, que antes de serem contempladas com a casa adaptada viviam em uma realidade de precariedade habitacional. Em termos de habitação, a mudança para as casas próprias e adaptadas dos conjuntos do MCMV deixou de ser um sonho, todavia, a nova casa veio acompanhada de mais dificuldades e obstáculos a serem ainda vencidos em função de sua localização periférica e da precariedade em termos de serviços e infraestrutura dos locais escolhidos. Com a mudança de moradia se esperavam transformações positivas em termos de desenvolvimento socioespacial.

0 programa, que poderia ter sido uma referência em termos de inclusão, acabou por tornar-se uma referência contrária, ou seja, uma referência em termos de exclusão socioespacial. No seu discurso, o programa aponta a garantia à acessibilidade das PcD ou mobilidade reduzida às atividades que incluam serviços, lazer, educação, saúde e participação do mercado de trabalho. Trata-se de uma promessa de efetiva inclusão socioespacial, se referindo também à infraestrutura adequada no espaço urbano, bem como, nos veículos públicos. Todavia, esse discurso permaneceu no papel, já que o programa não propiciou a acessibilidade das PcD ao conjunto habitacional como um todo e sua integração à cidade.

O papel do Estado frente a criações de políticas públicas para resolver as desigualdades sociais é ineficiente e frágil, o que se tem é a atuação de um Estado mínimo com base neoliberal que pouco avança em termos de projetos sociais. As políticas públicas deveriam prever e trazer avanços. Nas áreas mais afastadas da cidade, onde são implantados os empreendimentos para as famílias de baixa renda, entre elas o grupo das PcD, não há um planejamento intersetorial adequado e muito menos uma busca por melhorias no desenvolvimento e na qualidade de vida.

Assim, comparando-se os aspectos de inclusão entre os programas habitacionais implantados ao longo do tempo no espaço urbano de Ponta Grossa, concluiu-se que: a) dada a situação de precariedade de infraestrutura (equipamentos e serviços) dos conjuntos e sua localização periférica, há uma continuidade no processo de exclusão socioespacial de seus moradores. b) a mudança para a casa adaptada do MCMV, todavia, proporciona maior qualidade de vida para as PcD, garantindo sua inclusão no "espaço interior" da habitação. Tem-se, assim, a mudança de uma política pública de exclusão para uma de inclusão excludente.

${ }^{3}$ Informações cedidas pela Assistente social da Prolar, Novembro de 2013.

\section{Referências}

BARTALOTTI, C. C. Inclusão social das pessoas com deficiência: utopia ou possibilidade. São Paulo: Paulus, 2006.

\section{BEVERVANÇO, R. B. Direitos da pessoa portadora} de deficiência. Curitiba: Ministério público do estado do Paraná, 2001.

BIANCHETTI, L.; FREIRE, I. M. Um olhar sobre a diferença: interação, trabalho e cidadania. Campinas: Papirus, 1998.

CÂMARA DOS DEPUTADOS. 2013. Disponível em: $<$ camara.gov.br/.../bdcamara/.../legislacao_portadora_deficiencia_7ed.pdf.>. Acesso em: 13 Mai. 2013.

CORDEIRO, M. P. Ativismo e deficiência: um estudo sobre os repertórios que dão sentido à vida independente. Psicologia em revista, Belo Horizonte, v.15, n. 32, p. 114-131, Ago. 2009. Disponível em:< http://periodicos.pucminas.br/ index.php/psicologiaemrevista/article/view/ P.1678-9563.2009v15n2p114.> Acesso em: 12 Fev. 2013.

CRESPO, A. M. M. Da invisibilidade à construção da própria cidadania. Os obstáculos, as estratégias e as conquistas do movimento social das pessoas com deficiência no Brasil, através das histórias de vida de seus líderes. Tese de doutorado, FFLCH/USP, 2009. Disponível em:< www.teses.usp.br/teses/.../8/.../ ANA_MARIA_MORALES_CRESPO.pdf $>$. Acesso em: 23 Abr. 2013.

ESCOREL, S.; MOREIRA, M. R. Participação Social. In: GIOVANELLA, L.; ESCOREL, S.; LOBATO, L. V. C. Políticas e sistema de saúde no Brasil. Rio de Janeiro: FIOCRUZ, 2008.

FREITAS, M. N. C. Formas de ver as pessoas com deficiências: um estudo empírico do construto de concepções de deficiência em situações de trabalho. Revista ADM. Mackenzie, São Paulo, v. 11, n³, p.100-129, mai/jun. 2010.

GERALDO, G. P. O Programa Minha Casa Minha Vida, o mercado imobiliário e o direito à cidade: análise dos impactos do programa na cidade de São Carlos SP. In: Encontros de Geográficos da América latina. 2013, Lima-Peru. Anais: http://www.egal2013. pe/. Lima, 2013, p. 1-18.

GIRON, G. R. Políticas públicas, educação e neoliberalismo: o que isso tem haver com cidadania. Revista de educação PUC. Campinas, v.24, n. 34, p. 17-26, jun. 2008. 
HERMONT, L. D., RIBEIRO, R. G. Caderno de implantação de sistemas de transporte acessíveis. Brasília: Governo federal, 2006.

IBGE. Instituto Brasileiro de Geografia e estatística 2010. Disponível em:< http://www.ibge.gov.br/ censo/>. Acesso em: 02 Jun.2013.

Instituto Brasileiro de Geografia e estatística 1991. Disponível em:< http://www.ibge.gov.br/ censo/>. Acesso em: 21 Dez. 2014.

Instituto Brasileiro de Geografia e estatística 1970. Disponível em:< http://www.ibge.gov.br/ censo/>. Acesso em: 21 Dez. 2014.

Instituto Brasileiro de Geografia e estatística 1960 - Paraná. Disponível em:http://biblioteca. ibge.gov.br/visualizacao/periodicos/68/cd_1960_ v1_t14_pr.pdf. Acesso em: 21 Dez. 2014.

LANNA JÚNIOR, M. C. M. História do movimento político das Pessoas com Deficiência no Brasil. Brasília: Secretária dos direitos humanos. Secretária nacional de promoção dos direitos das pessoas com deficiência, 2010.

LOMBARDI, A, P. Inclusão socioespacial para Pessoas com Deficiência: os espaços de morar do programa "Minha Casa Minha Vida" na cidade de Ponta Grossa. PR. 2014. 173 f. Dissertação (Mestrado em Geografia), Universidade Estadual de Ponta Grossa, Ponta Grossa, 2014.

LOMBARDI, A. P., LÖWEN SAHR, C. L. Inclusão socioespacial de Pessoas com Deficiência: espaços de morar do "Programa Minha Casa Minha Vida" na cidade de Ponta Grossa-PR. Ateliê Geográfico, Góias, v.7, n.2, p.233-256, Ago./2013.

LÖWEN SAHR, C. L. Estrutura interna e dinâmica social na cidade de Ponta Grossa In: DITZEL, C. H. M. de; LÖWEN SAHR, C. L. Espaço e cultura: Ponta Grossa e os campos Gerais. Ponta Grossa: UEPG, 2001.

OMS - Organização Mundial da Saúde. Relatório Mundial da Deficiência. São Paulo: SEDPcD, 2012. Disponível em:< http://www.pessoacomdeficiencia.sp.gov.br/usr/share/documents/RELATORIO_ MUNDIAL_COMPLETO.pdf.> Acesso em: 3 Jun.2012.

PIANA, M. C. As políticas sociais no contexto brasileiro: natureza e desenvolvimento. São Paulo: cultura acadêmica, 2009.
PROLAR. Cadastro de Demanda de Habitação de Baixa Renda no Município de Ponta Grossa. Ponta Grossa: Prolar, s.d. (2010-2012).

SANTOS, M. Por uma Geografia Nova. 6. ed. São Paulo: Edusp, 2004.

O Espaço do cidadão. São Paulo: Nobel, 1987.

SASSAKI, R. K. Inclusão: construindo uma sociedade para todos. Rio de Janeiro: WVA, 1997.

SAWAIA, B. As artimanhas da exclusão: análise psicossocial e ética da desigualdade social. Petrópolis: Vozes, 2006.

SCHEFFER, M. S. Espaço urbano e política habitacional: uma análise sobre Ponta Grossa-Pr. 2001, 107 f. Mestrado (Mestrado em Ciências sociais aplicadas) UEPG, Ponta Grossa, 2003.

SILVA, M. I.; IACOBUCCI, D. L. Pessoas com deficiência na mídia: uma abordagem humanizada. Disponível em:< http://www.pessoacomdeficiencia. sp.gov.br/usr/share/documents/PCDnaMIDIA_Isabel.pdf>. Acesso em: 10 Mai. 2013.

SNPDPD - Secretaria Nacional de Promoção dos Direito das Pessoas com Deficiência. Deficiência, viver sem limite. Brasil: SDH, 2013.

SOUZA, M. L. de. A prisão e a Ágora: reflexões em torno da democratização do planejamento e da gestão das cidades. Rio de Janeiro: Bertrand Brasil, 2006.

TEIXEIRA, E. C. 0 Papel das políticas públicas no desenvolvimento local e na transformação da realidade. Bahia: AATR-BA, 2002.

VALERI, A. V. et al. Caderno implementação do Decreto $\mathrm{N}^{\circ}$ 5.296/04 - Para Construção da Cidade Acessível. 2004. Disponível em:< caixa.gov.br/_arquivos/assitencia_tecnica/acessibilidade/cad-3>. Acesso em: 12 Mai. 2013.

VACAREZZA, C. 2012. Disponível em:< http:// vaccarezza.com.br/programa-minha- casa-minha-vida-garante-padroes-de-acessibilidade/>. Acesso em: 30 Out. 2012.

VERÁS, M. Exclusão social: um problema brasileiro de 500 anos. In: SAWAIA, B. As artimanhas da exclusão: análise psicossocial e ética da desigualdade social. Petrópolis: Vozes, 2006. p. 27-50. 
INCLUSION BY EXCLUSION OF DISABLED PERSONS: FROM THE DISCOURSE ON CIVIL RIGHTS TO THE IMPLEMENTATION OF HOUSING POLICIES IN BRAZIL

\begin{abstract}
This article discusses the socio-spatial inclusion of disabled persons, focusing mainly on the comparison between discourse and practice in Brazilian public policies for handicapped persons. Its analytical approach investigates housing programs in the municipality of Ponta Grossa, state of Paraná (Brazil). The term "disabled person" (pessoa com deficiência) has been used in Brazil since 2008 to advocate equal rights and dignity for this sector in relation to all other sectors of society. In Brazilian housing policies, this term has been immediately applied in the Federal Program "Minha casa, minha vida" (My house, my life). This program guarantees the accessibility of disabled persons in its discourse. In practice, however, in assessing the succession of housing programs since 1970 in Ponta Grossa, no changes in the socio-spatial exclusion of this segment can be observed, even in its recent versions. What is different in relation to former programs is: a) the destination of specific units to disabled persons, and $b$ ) the adaptation of the internal environment of the respective houses to wheel chairs. In contrast, the access to outside infrastructure, equipment and public services does not meet the needs of disabled persons, excluding them from everyday life in the neighborhood and in the city. Thus, this segment can be said to experience an excluding inclusion in socio-spatial aspects.
\end{abstract}

Keywords: Socio-spatial inclusion, disabled persons, housing policies, Ponta Grossa (Paraná, Brazil).

\title{
LA INCLUSIÓN EXCLUYENTE DE PERSONAS CON DISCAPACIDAD: DEL DISCURSO DE CIUDADANÍA A LA PRÁCTICA EN LAS POLÍTICAS DE VIVIENDA EN BRASIL
}

\begin{abstract}
Resumen: En este artículo se presenta una reflexión sobre la inclusión socioespacial de personas con discapacidad. El objetivo central es evaluar el discurso y la práctica efectiva encuanto a la inclusión de esos sujetos en las políticas públicas brasileñas. La análisis se centra en los programas de vivienda y tiene como recorte espacial la ciudad de Ponta Grossa, situada en el estado de Paraná (Brasil). El término "persona con discapacidad" comienza a utilizarse en Brasil a partir de 2008 con la finalidad de defender la igualdad, en términos de derechos y dignidad,de dicho segmento de la población con respecto a los demás. En las políticas de vivienda, el término pasa a tener un empleo inmediato en el programa federal "Mi Casa, Mi Vida". El discurso que funda ese programa prevé la garantía a la accesibilidad para las personas con discapacidad. En la práctica efectiva, sin embargo, cuando se evalúa la sucesión de los programas de vivienda implantados en Ponta Grossa, se observa que la lógica de exclusión socioespacial no presenta ruptura a lo largo del tiempo, ni aun en el programa más reciente. Lo que diferencia ese programa de los anteriores es: a) la asignación de un porcentual de las viviendas a las personas con discapacidad; b) la adaptación del espacio interno de las casas para usuarios de sillas de ruedas. En lo que se refiere a la accesibilidad a la infraestructura, equipos y servicios públicos, ese segmento no es atendido, por lo que queda excluido de la vida en el barrio y la ciudad. Se asiste, así, a una inclusión excluyente de esos segmentos en términos socioespaciales.

Palabrasclave: Inclusión socioespacial, personas con discapacidad, políticas de vivienda, Ponta Grossa (Paraná, Brasil).
\end{abstract}

